\title{
Erectile function after robotic nerve sparing and semi-sparing of the neurovascular bundles
}

\author{
Andreas E. Nilsson · Stefan Carlsson • \\ N. Martin Jonsson • Eric Onelöv • Gunnar Steineck • \\ N. Peter Wiklund
}

Received: 9 July 2007 / Accepted: 17 July 2007 / Published online: 11 August 2007

(C) Springer London 2007

\begin{abstract}
We set out to present potency results after bilateral, unilateral, and semi-sparing of the neurovascular bundles after robotic prostatectomy. Two hundred and twentyfive consecutive robotic-assisted laparoscopic radical prostatectomies were performed by one surgeon (NPW) from the start of our robotic program in January 2002 until December 2005. Patient demographics, operative, and postoperative data were prospectively entered into a database. We have functional data for 183, 150, and 109 patients followed for 3, 6, and 12 months, respectively. Of 49 preoperatively potent patients $36(73 \%, 95 \%$ CI $59-85 \%)$ had erections sufficient for intercourse at 12 month follow-up. If bilateral nerve sparing was performed, $13(87 \%, 95 \% \mathrm{CI}$ $59-85 \%$ ) of the patients showed a return of potency sufficient for intercourse. In preoperatively potent patients who
\end{abstract}

There are no conflicts of interests for any of the authors; funding was provided by the ALF (funding of clinical research by Stockholm County Council).

A. E. Nilsson · S. Carlsson · N. M. Jonsson · N. P. Wiklund Department of Molecular Medicine and Surgery,

Section of Urology, Karolinska Institute, Stockholm, Sweden

E. Onelöv · G. Steineck

Department of Oncology and Pathology,

Section of Clinical Cancer Epidemiology,

Karolinska Institute, Stockholm, Sweden

G. Steineck

Department of Oncology,

Division of Clinical Cancer Epidemiology,

Sahlgrenska Academy, Göteborg, Sweden

\section{A. E. Nilsson $(\square)$}

Department of urology, Karolinska University Hospital,

Stockholm 171 76, Sweden

e-mail: andreas.nilsson@karolinska.se did not undergo a traditional nerve sparing due to a highrisk disease, semi-sparing of the neurovascular bundles showed a return of potency in $10(53 \%, 95 \%$ CI $29-76 \%)$. After one-year follow-up, 66 of 71 (93\%, 95\% CI 84-98\%) had no need for protective pads and two (3\%) used more than one pad a day. In the first 100 patients there were 24 (24\%) positive surgical margins and for the last 125 patients there were $18(14 \%)$. Based on these data, we hypothesize that certain subgroups, e.g., men wanting to preserve their sexual potency but having a tumor that hinders a traditional nerve-sparing approach, may be particularly helped by robot-assisted laparoscopic surgery as compared with other techniques.

Keywords Laparoscopy · Nerve-sparing · Prostatectomy · Potency $\cdot$ Robotics

\section{Introduction}

Radical prostatectomy is an effective treatment for localized prostate cancer, reducing overall and disease-specific mortality [1]. However, the number of men that must be treated to prevent one death from prostate cancer is high. A randomized trial found no impact on the average level of self-assessed quality of life after four years of follow-up [2]. Urinary leakage and erectile dysfunction occurring as a consequence of radical prostatectomy reduces quality of life [3]. So, reducing the percentage of men contracting erectile dysfunction after radical prostatectomy may improve self-assessed quality of life for prostate-cancer survivors.

Robot-assisted laparoscopic prostatectomy has been claimed to achieve excellent potency outcomes when a nerve-sparing procedure is performed [4]. Nevertheless a 
substantial fraction of patients choose radical prostatectomy where a traditional nerve-sparing procedure cannot be recommended due to the high-risk tumour and consequent risk of positive surgical margin.

We present a novel technique of semi-nerve-sparing in these high-risk patients.

\section{Methods}

Between the initiation of our robotic program in January 2002 and December 2005, 225 consecutive patients underwent robot-assisted laparoscopic radical prostatectomy by a single surgeon (NPW). The indications for robotic surgery are identical to open surgery at our institution. The surgeon had extensive experience of open radical prostatectomy but lacked laparoscopic experience before commencing with robotic surgery.

Our surgical technique has been previously described [5]. Five transperitoneal ports are placed: three for the robotic system and two for the assisting surgeon. Posterior dissection of the vasa deferentia and seminal vesicles is performed. The seminal vesicle tips are spared during full nerve-sparing procedures to avoid undue trauma to the neurovascular bundles, which may come into proximity with the lateral tips of the seminal vesicles [6]. The Denonvilliers fascia is opened and the plane between the Denonvilliers fascia and the perirectal fat is developed. After mobilizing the urinary bladder, the endopelvic fascia is incised. A bladder-neck-sparing dissection is thereafter preformed. During nerve-sparing procedures clips are applied when dividing the vascular pedicles, avoiding any thermal heat near the neurovascular bundles. When traditional nerve sparing is planned an interfacial technique is preferred. In patients with high-volume disease, a seminerve-sparing technique is preformed. Our semi-sparing technique involves dissection in a plane within the neurovascular bundles that thereby leaves a rim of neurovascular tissue on the prostatic surface, but leaves a substantial amount of the neurovascular bundles (NVB) intact in the patient. Semi-sparing was performed either bilaterally or unilaterally if traditional nerve sparing was performed on the contra-lateral side. Clips were applied during dissection to avoid thermal trauma to the erectile nerves. The dorsal venous complex was sharply divided and thereafter oversewn. Anastomosis was performed with a running suture as described by Van Velthoven [7].

Operating times and other perioperative parameters were collected prospectively. Tumor margins and specimen status were collected from standard pathology reports. Positive margin was defined as tumor cells present at the inked surface. Focally positive surgical margins were defined as $3 \mathrm{~mm}$ or less of tumor present at the inked surface in one section, and nonfocal positive margins were defined as tumor exceeding $3 \mathrm{~mm}$ at the inked surface in one or more sections. A self-administered questionnaire regarding urinary and potency status was mailed to the patients 3,6 , and 12 months after surgery. After the 46th patient in the series, questionnaires were also mailed preoperatively.

The patients were asked to complete the questionnaire and to send it to a research nurse for data collection. The questionnaire was composed of simple questions asking, e.g., do you experience urinary leakage and how many protective pads do you need during an ordinary day? Concerning potency the question was worded as, when sexually aroused, were erections sufficient for sexual penetration, with five possible answers ranging from never to always. We defined potency as the ability to perform sexual penetration in at least half of attempts with or without the use of phosphodiesterase (PDE) inhibitors. Urinary continence was evaluated with the use of protective pads. Eleven patients did not receive a questionnaire and we thus cannot asses the functional outcome for them. The numbers of patients followed for 3, 6, and 12 months were 183,150 , and 109 , respectively.

Data was prospectively entered into a database. For prevalence, we calculated a $95 \%$ confidence interval (CI) which was calculated using an augmenting binominal distribution.

\section{Results}

Among the 225 patients, the mean age was 61.7 (range 3675) years, mean prostate specific antigen (PSA) was 7.9 (1.5-21) $\mathrm{ng} \mathrm{ml}^{-1}$, and mean preoperative Gleason score was 6.2 (4-9). Overall $60.4 \%$ were staged as $\mathrm{T} 1,36.9 \%$ were staged as $\mathrm{T} 2$, and $2.7 \%$ were staged as having $\mathrm{T} 3$ disease (Table 1). There were $24(24 \%)$ positive surgical margins in the first 100 patients, 16 of which were extensively positive and eight of which were focally positive. In the last 125 patients there were $14 \%$ positive surgical margins: six (4.8\%) extensively positive and $11(8.8 \%)$ focally positive. There were nine $(10.6 \%)$ positive margins in pT2 tumours

Table 1 Baseline characteristics for 225 patients operated with robotassisted laparoscopic radical prostatectomy

\begin{tabular}{lll}
\hline Variable & $\begin{array}{l}\text { Patients 1-100, } \\
\text { number (\%) }\end{array}$ & $\begin{array}{l}\text { Patients 101-225, } \\
\text { number }(\%)\end{array}$ \\
\hline Mean age, years (range) & $61(36-71)$ & $62.3(46-75)$ \\
$\begin{array}{l}\text { Mean PSA, ng ml } \\
\text { Mean preoperative }\end{array}$ & $6.5(0.5-15)$ & $7.4(1.1-21)$ \\
$\quad$ Gleason score (range) & & $6.3(5-9)$ \\
T1c tumours (\%) & $64(64 \%)$ & $71(56.8 \%)$ \\
T2 tumours (\%) & $31(31 \%)$ & $53(42.4 \%)$ \\
T3 tumours (\%) & $5(5 \%)$ & $1(0.8 \%)$ \\
Volume, ml (range) & $36.6(15.5-90)$ & $45.9(14-177)$ \\
\hline
\end{tabular}


and nine $(22 \%)$ positive margins in pT3 tumours in the last 125 cases (Table 2 ).

With potency defined as erections sufficient for penetration in at least half of attempts, 84 patients out of 168 were defined as preoperatively potent. When bilateral nerve sparing was attempted, 19 (52.8\%), 15 (57.7\%), and $13(86.7 \%)$ patients had return of potency after 3,6 , and 12 months, respectively. In men who were unilaterally nerve spared the figures were eight (32\%), 11 (44\%), and $13(86.7 \%)$ patients with a return to potency after 3,6 , and 12 months, respectively. In preoperatively potent patients who underwent semi-sparing of both neurovascular bundles, due to an advanced tumour, four (17.4\%), four (20\%) and $10(52.6 \%)$ had a return to potency at 3,6 , and 12 months, respectively (Table 3, 4).

Three months after surgery $90(66.2 \%)$ of the patients reported that they did not need protective pads for urinary leakage, $29(21.3 \%)$ reported the use of one pad per day, and $17(12.5 \%)$ needed more than one pad. At 6 months follow-up $114(85.1 \%)$ reported no use of protective pads, $13(9.7 \%)$ needed pads for security reasons, and seven (5.2\%) needed to change pads. Twelve months after surgery $66(93 \%)$ reported no need for protective pads and three $(4.3 \%)$ used one pad per day (Table 5).
Table 2 Pathology for 225 patients operated with robotassisted laparoscopic radical prostatectomy

\begin{tabular}{lll}
\hline Variable & $\begin{array}{l}\text { Patients 1-100, } \\
\text { number }(\%)\end{array}$ & $\begin{array}{l}\text { Patients 101-225, } \\
\text { number (\%) }\end{array}$ \\
\hline pT2 tumours & $64(64)$ & $85(68)$ \\
pT3 tumours & $36(36)$ & $40(32)$ \\
Extensive positive margins & $16(16)$ & $7(5.6)$ \\
Focal positive margins & $8(8)$ & $11(8.8)$ \\
Positive margins in pT2 tumours & $11(17.2)$ & $9(10.6)$ \\
Positive margins in pT3 tumours & $13(36.1)$ & $9(22.5)$ \\
\hline
\end{tabular}

Table 3 Potency data 3, 6, and 12 months after robot-assisted laparoscopic radical prostatectomy

\begin{tabular}{lllll}
\hline $\begin{array}{l}\text { Months } \\
\text { after surgery }\end{array}$ & $\begin{array}{l}\text { Bilaterally nerve } \\
\text { spared, no./tot. no. (\%) }\end{array}$ & $\begin{array}{l}\text { Unilaterally nerve } \\
\text { spared, no./tot. no. }(\%)\end{array}$ & $\begin{array}{l}\text { Partial resection of NVB, } \\
\text { no./tot. no. (\%) }\end{array}$ & $\begin{array}{l}\text { Follow-up } \\
\text { rate }(\%)\end{array}$ \\
\hline 3 months & $19 / 36(52.8)$ & $8 / 24(33.3)$ & $4 / 23(17.4)$ & 92.4 \\
6 months & $15 / 26(57.7)$ & $11 / 24(45.8)$ & $4 / 20(20)$ & 84.5 \\
12 months & $13 / 15(86.7)$ & $13 / 15(86.7)$ & $10 / 19(52.6)$ & 95.8 \\
\hline
\end{tabular}

Defined as the ability to have erections sufficient for penetration in at least half of attempts with or without the use of PDE inhibitors

Table 4 Oncological data for patients who were evaluated as potent preoperatively

Table 5 Continence data after 3,6 , and 12 mounts after robotassisted laparoscopic radical prostatectomy

\begin{tabular}{|c|c|c|c|}
\hline Variable & $\begin{array}{l}\text { Bilaterally } \\
\text { nerve spared }\end{array}$ & $\begin{array}{l}\text { Unilaterally } \\
\text { nerve spared }\end{array}$ & $\begin{array}{l}\text { Partial resection } \\
\text { of NVB }\end{array}$ \\
\hline Age (range) & $59.8(46-71)$ & $60.4(53-74)$ & $63.5(59-72)$ \\
\hline PSA ng ml ${ }^{-1}$ (range) & $6.6(2.7-21)$ & $6.6(1.1-14)$ & $8.5(3.2-17)$ \\
\hline T1c tumours $(\%)$ & $30 / 36(83.3 \%)$ & $11 / 24(45.8 \%)$ & $10 / 23(43.5 \%)$ \\
\hline $\mathrm{T} 2$ tumours $(\%)$ & $6 / 36(16.6 \%)$ & $13 / 24(54.2 \%)$ & $11 / 23(47.8 \%)$ \\
\hline $\mathrm{T} 3$ tumours $(\%)$ & $0 / 36$ & $0 / 24$ & $2 / 23(8.7 \%)$ \\
\hline Gleason score (preoperatively) $\leq 6$ & $32 / 36(88.9 \%)$ & $19 / 24(79.2 \%)$ & $16 / 23(69.6 \%)$ \\
\hline$=7$ & $4 / 36(11.1)$ & $3 / 24(12.5 \%)$ & $6 / 23(26.1 \%)$ \\
\hline$\geq 8$ & $0 / 36$ & $2 / 24(8.3 \%)$ & $1 / 23(4.4 \%)$ \\
\hline pT3 tumours $(\%)$ & $7 / 36(24.1 \%)$ & $5 / 24(20.8 \%)$ & $13 / 23(56.5 \%)$ \\
\hline Positive margins (\%) & $7 / 36(24.1 \%)$ & $4 / 24(16.7 \%)$ & $4 / 23(15.7 \%)$ \\
\hline
\end{tabular}

\begin{tabular}{lllll}
\hline $\begin{array}{l}\text { Months after } \\
\text { surgery (months) }\end{array}$ & $\begin{array}{l}\text { No pads, } \\
\text { no. }(\%)\end{array}$ & $\begin{array}{l}\text { One pad } \\
\text { per day, no. }(\%)\end{array}$ & $\begin{array}{l}\text { Wet pads, } \\
\text { no. }(\%)\end{array}$ & $\begin{array}{l}\text { Follow-up } \\
\text { rate }(\%)\end{array}$ \\
\hline 3 & $90(66.2)$ & $29(21.3)$ & $17(12.5)$ & 74.3 \\
6 & $114(85.1)$ & $13(9.7)$ & $7(5.2)$ & 81.2 \\
12 & $66(93)$ & $3(4.3)$ & $2(2.7)$ & 65.1 \\
\hline
\end{tabular}


The mean robotic operating time was $113.2(55-341) \mathrm{min}$ and the mean estimated blood loss was $158(50-1,200) \mathrm{ml}$. One patient required conversion to an open procedure (case number 9) due to lack of progress. Two patients developed strictures in the anastomosis, necessitating dilation. Seven major complications occurred in the series. Four patients were taken back to the operating room, due to postoperative haemorrhage in two and catheter problems in two. A ureteral injury occurred in the first case of the series, requiring subsequent open ureteral reimplantation. One patient needed bilateral percutaneous nephrostomy due to an anastomotic leakage. One patient experienced temporary femoral nerve palsy.

\section{Discussion}

Strictly it is impossible to draw any conclusions from this single-surgeon series without a concurrent comparison group concerning oncological and functional outcomes. Robotic prostatectomy, as performed in this study, resulted in the preservation of potency in the majority $(73 \%)$ of preoperatively potent patients at 1 year follow-up, irrespective of whether traditional nerve-sparing or a semi-sparing approach was performed. A return to potency was seen in 87,87 , and $53 \%$ in the bilaterally nerve-spared, unilaterally nerve-spared, and semi-spared groups, respectively.

We were encouraged by finding that 10 out of 19 men classified as sexually potent before surgery, and in whom the surgeon did not try to extensively preserve either of the two neurovascular bundles, had preserved sexual potency one year postoperatively. One can speculate that the enhanced visualization of the anatomical structures with the robotic system admits semi-sparing of the neurovascular bundles in the subset of patients with a high-risk disease, where traditional nerve sparing is usually not preformed because of the high risk of positive margins. If the dissection is kept in a plane within the neurovascular bundles and if the surgeon avoids thermal trauma by diathermy, preservation of the erectile function may be achieved without an increased incidence of positive surgical margins in this subset of high-risk patients. It has previously been reported that a return to potency occur in a majority of patients when traditional nerve-sparing, whether bilateral or unilateral, is performed, but to our knowledge this has not been reported when traditional nerve sparing has not been performed even though a return to potency in up to $38 \%$ of the non-nerve-spared patients is seen after open surgery $[8,9]$. So, based on the data from the 19 men in this series, we hypothesise that robotassisted laparoscopic surgery is particularly beneficial for men giving full priority to optimal survival length over avoiding therapy-induced erectile dysfunction, but who nevertheless would have a better quality of life with preserved erectile function. Of course we need more data than from this small group before we can judge whether or not semi-sparing of nerve bundles can be done with intact function one year later.

There are numerous reports with excellent potency outcomes after open and minimal invasive surgery $[9,10,11]$. Menon reports a $97 \%$ potency rate after a nerve-sparing robotic procedure, of which $71 \%$ had recovered normal erectile function one year after surgery [4]. Walsh reported a potency rate of $86 \% 18$ months after nerve-sparing retropubic radical prostatectomy, and Catalona reported a $76 \%$ potency rate after bilateral nerve sparing in 1,770 patients $[12,13]$. Montorsi reports a $52 \%$ potency rate after only six months follow-up [14]. All men in these series were operated by a single high-profile surgeon at a high-volume institution. However, the results may reflect the capacity of the surgical technique involved.

Quality-of-life studies after radical prostatectomy show less encouraging results when including non-nerve-sparing procedures. Historical data from Sweden, including both nerve-spared and non-nerve-spared patients, show a potency rate of $20 \%$ four years after surgery [2]. Data from CaPSURE show that only $20 \%$ reach baseline potency one year after surgery [15]. Theoretically it seems that much can be gained if nerve sparing or semi-sparing could be performed in all preoperatively potent patients that choose radical prostatectomy.

We present all consecutive patients operated by one surgeon with no previous laparoscopic experience with a novel technique. There is inevitably a learning-curve effect to be overcome, even though reports have shown a shorter learning curve for robot-assisted laparoscopic radical prostatectomy compared with standard laparoscopy [16-19]. We therefore anticipate that increasing experience with the procedure will translate into further improvements in oncological and functional outcome.

We hypothesize that certain subgroups, e.g., men with a tumor, which precludes saving the neurovascular bundles in extenso, and wanting to maintain erectile function, are particularly helped by robotic instead of open surgery.

\section{References}

1. Bill-Axelsson A, Holmberg L, Ruutu M et al (2005) Radical prostatectomy versus watchful waiting in early prostate cancer. N Engl J Med 352:1977-1984

2. Steineck G, Helgesen F, Adolfsson J et al (2002) Quality of life after radical prostatectomy or watchful waiting. $\mathrm{N}$ Engl J Med 347:790-796

3. Helgason A, Adolfsson J, Dickman P et al (1998) Distress due to unwanted side-effects of prostate cancer treatment is related to impared well-being (quality of life). Prostate Cancer Prostatic Dis 1:128-133 
4. Kaul S, Savera A, Badani K et al (2006) Functional outcomes and oncological efficacy of Vattikuti institute prostatectomy with veil of Aphrodite nerve-sparing: an analysis of 154 consecutive patients. BJU Int 97:467-472

5. Nilsson AE, Carlsson S, Laven BA et al (2006) Karolinska prostatectomy: a robot-assisted laparoscopic radical prostatectomy technique. Scand J Urol Nephrol 40:453-458

6. Tewari A, Peabody JO, Fischer M et al (2003) An operative and anatomic study to help in nerve sparing during laparoscopic and robotic radical prostatectomy. Eur Urol 43:444-454

7. Van Velthoven Rf, Ahlering TE, Peltier A et al (2003) Technique for laparoscopic running urethrovesical anastomosis: the single knot method. Urology 61:699-702

8. Stanford JL, Feng Z, Hamilton AS et al (2000) Urinary and sexual function after radical prostatectomy for clinically localized prostate cancer. JAMA 283:354-360

9. Salomon L, Anastasiadis AG, Katz R et al (2002) Urinary continence and erectile function: a prospective evaluation of functional results after radical prostatectomy. Eur Urol 42:338-342

10. Anastasiadis AG, Salomon L, Katz R et al (2003) Radical retropubic versus laparoscopic prostatectomy: a prospective comparison of functional outcome. Urology 62:292-297

11. Graefen M, Walz J, Huland H (2006) Oprn retropubic nervesparing radical prostatectomy. Eur Urol 49:38-48
12. Walsh PC, Marschke P, Ricker D et al (2000) Patient-reported urinary continence and sexual function after anatomic radical prostatectomy. Urology 55:58-61

13. Kundu SD, Roehl KA, Eggener SE et al (2004) Potency, continence and complications in 3,477 consecutive radical retropubic prostatectomies. J Urol 172:2227-2231

14. Montorsi F, Salonia A, Suardi N et al (2005) Improving the preservation of the urethral spincter and neurovascular bundles during open radical retrpubic prostatectomy. Eur Urol 48:938-945

15. Hu JC, Elkin EP, Pasta DJ et al (2004) Predicting quality of life after radical prostatectomy: results from capsure. J Urol 171:703707

16. Ahlering T, Skarecky, Lee D et al (2003) Successful transfer of open surgical skills to a laparoscopic environment using a robotic interface: initial experience with laparoscopic radical prostatectomy. J Urol 170:1738-1741

17. Eden CG, Cahill D, Vass J et al (2002) Laparoscopic radical prostatectomy: the initial UK series. BJU Int 90:876-882

18. Turk I, Deger S, Winkelmann B et al (2001) Laparoscopic radical prostatectomy: technical aspects and experience with 125 cases. Eur Urol 40:46-53

19. Carlsson S, Nilsson A, Wiklund NP (2006) Urinary incontinence after robot assisted laparoscopic radical prostatectomy. Scand J Urol 40:103-107 